\title{
An improved high-quality draft genome sequence of Carnobacterium inhibens subsp. inhibens strain $\mathrm{K} 1^{\top}$
}

\author{
Wayne L. Nicholson ${ }^{1 *}$, Christina L. Davis ${ }^{1}$, Nicole Shapiro ${ }^{2}$, Marcel Huntemann ${ }^{2}$, Alicia Clum² ${ }^{2}$, T. B. K. Reddy ${ }^{2}$, \\ Manoj Pillay ${ }^{3}$, Victor Markowitz ${ }^{3}$, Neha Varghese ${ }^{2}$, Amrita Pati ${ }^{2}$, Natalia Ivanova ${ }^{2}$, Nikos Kyrpides ${ }^{2,4}$ \\ and Tanja Woyke ${ }^{2}$
}

\begin{abstract}
Despite their ubiquity and their involvement in food spoilage, the genus Carnobacterium remains rather sparsely characterized at the genome level. Carnobacterium inhibens $\mathrm{K}^{\top}$ is a member of the Carnobacteriaceae family within the class Bacilli. This strain is a Gram-positive, rod-shaped bacterium isolated from the intestine of an Atlantic salmon. The present study determined the genome sequence and annotation of Carnobacterium inhibens $\mathrm{K}^{\top}{ }^{\top}$. The genome comprised 2,748,608 bp with a G + C content of $34.85 \%$, which included 2621 protein-coding genes and 116 RNA genes. The strain contained five contigs corresponding to presumptive plasmids of sizes: 19,$036 ; 24,250 ; 26,581 ; 65,272$; and 65,904 bp.
\end{abstract}

Keywords: Carnobacterium inhibens subsp. inhibens strain $\mathrm{K} 1^{\top}$

\section{Introduction}

The genus Carnobacterium was proposed in 1987 to encompass a group of closely related bacteria originally classified as unusual species of Lactobacillus [1,2]. The genus Carnobacterium includes heterofermentative, facultatively anaerobic, psychrotolerant, either motile or non-motile, Gram-positive rod-shaped lactic acid bacteria that produce mostly L-lactic acid by fermentation from glucose [3]. At present the genus contains 11 species with validly published names, which can be roughly divided into two groups. As the genus name implies, most Carnobacterium species (Carnobacterium divergens, Carnobacterium gallinarum, Carnobacterium inhibens, Carnobacterium jeotgali, Carnobacterium maltaromaticum, Carnobacterium mobile, Carnobacterium viridans) belong to a group that were originally isolated from biological sources such as living fish or foods derived from animal sources [4]. A second group of Carnobacterium spp. has been isolated from cold, low-nutrient environments such as Antarctic ice lakes (C. funditum, C. alterfunditum, C. iners) $[5,6]$ or

\footnotetext{
* Correspondence: WLN@ufl.edu

${ }^{1}$ Department of Microbiology and Cell Science, Institute of Food and Agricultural Sciences, University of Florida, Merritt Island, FL 32953, USA Full list of author information is available at the end of the article
}

Arctic permafrost (C. pleistocenium, C. inhibens subsp. gilichinskyi) $[7,8]$. Owing to an upsurge in investigations involving Carnobacterium strains isolated from novel environments, at present genome sequences have been published for the following Carnobacterium environmental strains: Carnobacterium sp. 17-4 isolated from permanently cold sea water [9]; C. maltaromaticum strain ATCC 35586 isolated from a diseased salmon [10]; C. maltaromaticum strain LMA 28 isolated from ripened soft cheese [11]; and C. inhibens subsp. gilichinskyi isolated from Siberian permafrost $[8,12]$. However, to date only one published report of a genome sequence from a type strain of Carnobacterium has appeared, from $C$. jeotgali strain $\mathrm{MS}^{\mathrm{T}}$ isolated from salt-fermented shrimp [13]. As part of a larger project to determine the genome sequences of all type strains of the genus Carnobacterium, the present study determined the classification and features of Carnobacterium inhibens subsp. inhibens strain $\mathrm{K} 1^{\mathrm{T}}[8]$ as well as its genome sequence and gene annotations.

\section{Organism Information}

Classification and features

Carnobacterium inhibens subsp. inhibens strain $\mathrm{K} 1^{\mathrm{T}}$ $\left(=\right.$ DSM $\left.13024^{\mathrm{T}}=\mathrm{JCM} 16168^{\mathrm{T}}\right)$ is the type strain of 
the species C. inhibens $[8,14]$. The strain was isolated from the intestine of an Atlantic salmon [14]. The species epithet was derived from the Latin verb inhibeo, meaning "to inhibit", referring to the growth-inhibitory activity that the bacterium shows [14]. Recent discovery of $C$. inhibens strain WN1359 from Siberian permafrost [15] prompted a re-examination of strains $\mathrm{K} 1^{\mathrm{T}}$ and $\mathrm{WN} 1359$, resulting in the proposal to rename the $\mathrm{K}^{\mathrm{T}}$ type strain as C. inhibens subsp. inhibens and the permafrost isolate $C$. inhibens subsp. gilichinskyi [8].

Carnobacterium inhibens subsp. inhibens strain $\mathrm{K}^{\mathrm{T}}$ is a motile Gram-positive rod (Fig. 1). It is a psychrophile that lacks both catalase and oxidase, does not grow on acetate containing media, but grows at $\mathrm{pH} 9$ and in Trypticase Soy Broth containing up to $6 \%(\mathrm{w} / \mathrm{v})$ sodium chloride. Strain $\mathrm{K} 1^{\mathrm{T}}$ is facultatively anaerobic and tryptone as a sole source of nutrient promotes growth. The most abundant cellular fatty acid of strain $\mathrm{K}^{\mathrm{T}}$ is oleic acid (18:1cis9) [14]. Classification of strain $\mathrm{K}^{\mathrm{T}}$ according to the MIGS recommendations published by the Genome Standards Consortium is presented in Table 1.

C. inhibens subsp. inhibens strain $\mathrm{K}^{\mathrm{T}}$ [8] was obtained from the German Collection of Microorganisms and Cell Cultures as strain DSM 13024. The strain was subcultured once and was stored as a $-70{ }^{\circ} \mathrm{C}$ frozen glycerol stock in the corresponding author's strain collection as strain WN1362. DNA isolated from strain WN1362 corresponding to $16 \mathrm{~S}$ rRNA gene sequences was PCR amplified with universal bacterial primers B27F (5'-GAGTTTGA TCMTGGCTCAG-3') and B1512R (5'-AAGGAGGTGA TCCANCCRCA-3') as described previously [16] and sequenced at the University of Florida Interdisciplinary Center for Biotechnology Research (UF-ICBR). The sequence was compared with those obtained using NCBI BLAST [17] with the default settings (only highly similar sequences). The most frequently occurring genera were Carnobacterium (17 \%) and unidentified bacteria (83 \%)

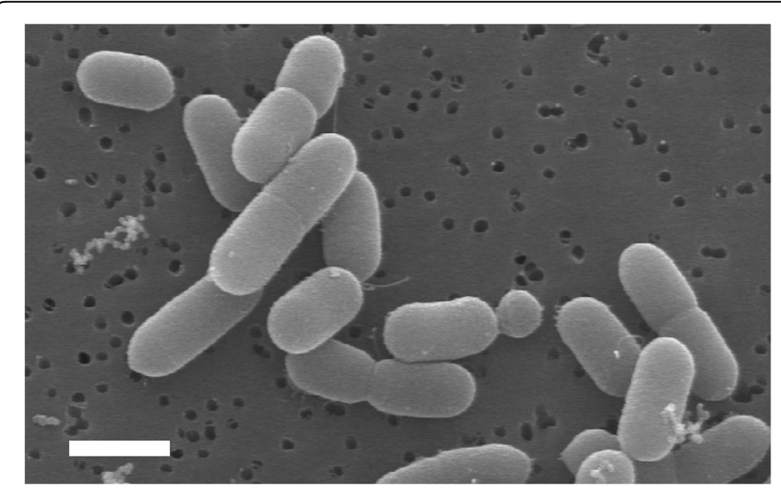

Fig. 1 Scanning electron micrograph of Carnobacterium inhibens subsp. inhibens strain $\mathrm{K}^{\top}$. Size bar is $1 \mu \mathrm{m}$ in length
Table 1 Classification and general features of Carnobacterium inhibens strain $\mathrm{K}^{\top}$ according to the MIGS recommendations published by the Genome Standards Consortium [20]

\begin{tabular}{|c|c|c|c|}
\hline MIGS ID & Property & Term & $\begin{array}{l}\text { Evidence } \\
\text { code }^{\mathrm{a}}\end{array}$ \\
\hline & \multirow{9}{*}{$\begin{array}{l}\text { Current } \\
\text { classification }\end{array}$} & Domain: Bacteria & \\
\hline & & Phylum: Firmicutes & TAS [34] \\
\hline & & Class: Bacilli & TAS $[35,36$ \\
\hline & & Order: Lactobacillales & TAS $[35,37$ \\
\hline & & Family: Carnobacteriaceae & $\operatorname{TAS}[35,38$ \\
\hline & & Genus: Carnobacterium & TAS [1] \\
\hline & & $\begin{array}{l}\text { Species: Carnobacterium } \\
\text { inhibens }\end{array}$ & TAS [14] \\
\hline & & $\begin{array}{l}\text { Subspecies: Carnobacterium } \\
\text { inhibens subsp. inhibens }\end{array}$ & TAS [8] \\
\hline & & Type strain: $\mathrm{K} 1^{\top}$ (DSM 13024) & \\
\hline & Gram stain & Positive & TAS [14] \\
\hline & Cell shape & Rod & $\operatorname{TAS}[8,14]$ \\
\hline & Motility & Motile & TAS [14] \\
\hline & Sporulation & Non-spore forming & $\operatorname{TAS}[8,14]$ \\
\hline & Temperature range & $0-37^{\circ} \mathrm{C}$ & TAS [8] \\
\hline & $\begin{array}{l}\text { Optimum } \\
\text { temperature }\end{array}$ & $35^{\circ} \mathrm{C}$ & TAS [8] \\
\hline & $\begin{array}{l}\mathrm{pH} \text { range; } \\
\text { Optimum }\end{array}$ & $6-9 ; 8.2$ & TAS [8] \\
\hline & Carbon source & Tryptone, & TAS [14] \\
\hline MIGS-6 & Habitat & $\begin{array}{l}\text { Gastrointestinal tract of fish } \\
\text { (Atlantic salmon) }\end{array}$ & TAS [14] \\
\hline MIGS-6.3 & Salinity & Grows at $0-6 \% \mathrm{NaCl}(\mathrm{w} / \mathrm{v})$ & $\operatorname{TAS}[8,14]$ \\
\hline MIGS-22 & $\begin{array}{l}\text { Oxygen } \\
\text { requirement }\end{array}$ & $\begin{array}{l}\text { Facultative anaerobe; grows } \\
\text { better in absence of } \mathrm{O}_{2}\end{array}$ & $\begin{array}{l}\text { TAS } \\
{[8,14,15]}\end{array}$ \\
\hline MIGS-15 & Biotic relationship & Unknown & \\
\hline MIGS-14 & Pathogenicity & Unknown & \\
\hline MIGS-4 & $\begin{array}{l}\text { Geographic } \\
\text { location }\end{array}$ & Göteborg, Sweden & \\
\hline MIGS-5 & Sample collection & Unknown & \\
\hline MIGS-4.1 & Latitude & Unknown & \\
\hline MIGS-4.2 & Longitude & Unknown & \\
\hline MIGS-4.3 & Depth & Unknown & \\
\hline MIGS-4.4 & Altitude & Below ocean surface & TAS [14] \\
\hline
\end{tabular}

avidence codes - IDA Inferred from Direct Assay, TAS Traceable Author Statement (i.e., a direct report exists in the literature), NAS Non-traceable Author Statement (i.e., not directly observed for the living, isolated sample, but based on a generally accepted property for the species, or anecdotal evidence). These evidence codes are from the Gene Ontology project [39]

(100 hits in total). The species with the Max score was Carnobacterium inhibens subsp. inhibens strain $\mathrm{K}^{\mathrm{T}}$ (NCBI Reference Sequence NR_036895) with a shared identity of $100.0 \%$, thus verifying the identity of strain WN1362 with the type strain. An updated 16S rRNA phylogenetic analysis of Carnobacterium spp. isolates including $C$. inhibens subsp. inhibens strain $\mathrm{K}^{\mathrm{T}}$ is presented in Fig. 2 to supplement and expand upon those published previously $[8,14,15]$. 


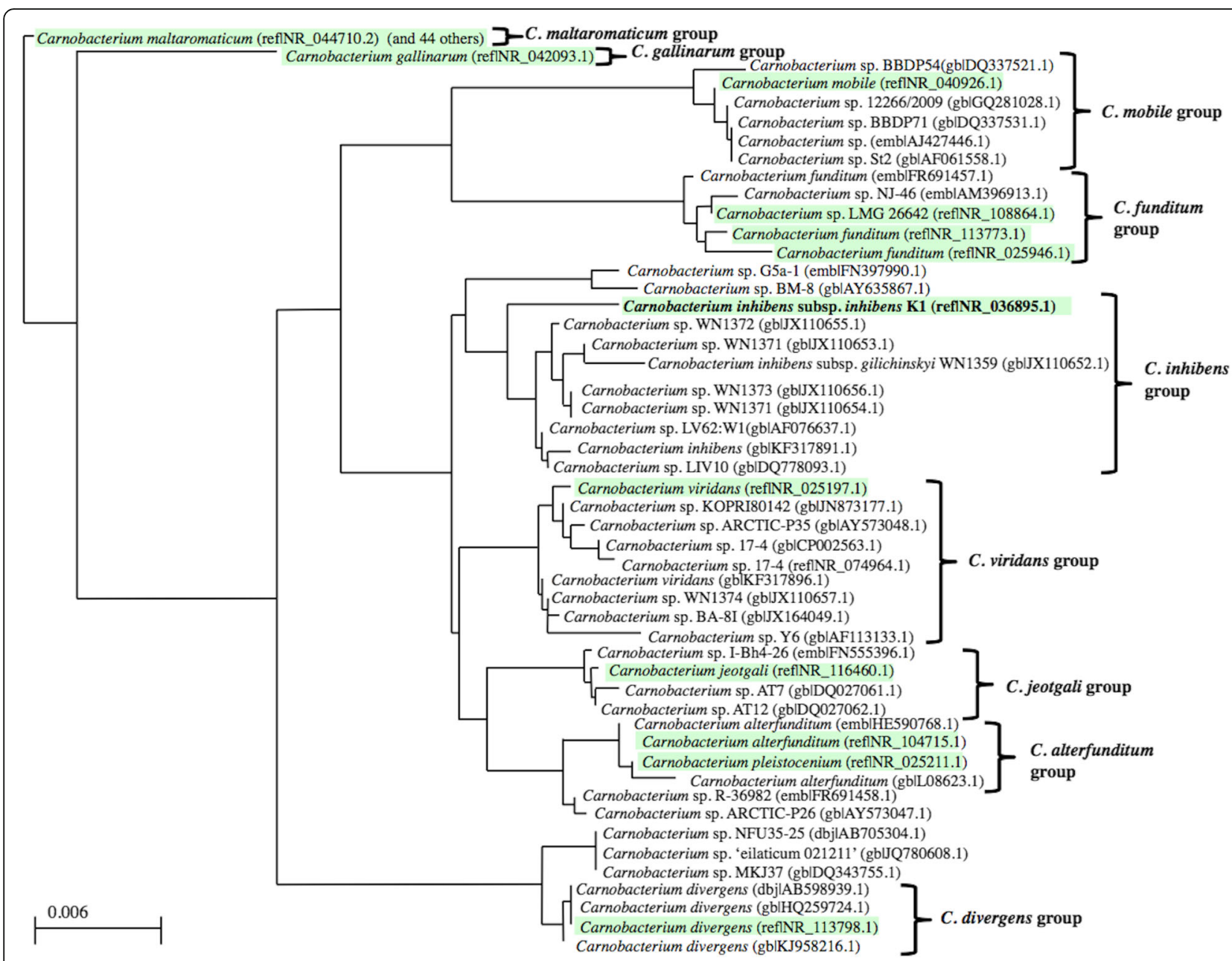

Fig. 2 Phylogenetic tree highlighting the position of Carnobacterium inhibens subsp. inhibens strain $\mathrm{K} 1^{\top}$ relative to other type (green boxes) and non-type strains within the genus Carnobacterium. Accession numbers are in parentheses: dbj, Database of Japan; emb, EMBL database; gb, NCBI Genbank. The top 100 hits by NCBI-BLASTN were input into the Distance Tree function at NCBI [33]. Alignments were converted to a distance matrix using the Jukes-Cantor distance correction model and the tree was constructed using the Neighbor-Joining method

\section{Genome sequencing information \\ Genome project history}

This organism was selected for sequencing on the basis of its relevance to environmental issues in phylogenetic diversity, bioenergy, and bioremediation, and is part of the Community Sequencing Program at the U.S. Department of Energy, Joint Genome Institute for projects of relevance to agency missions (http://www.jgi.doe.gov). The project is registered in the Genomes OnLine Database [18] and the permanent draft genome sequence is deposited in GenBank. Draft sequencing and assembly were performed at JGI using state of the art sequencing technology [19]. A summary of the project information is shown in Table 2, which presents the project information and its association with MIGS version 2.0 compliance [20].
Table 2 Carnobacterium inhibens subsp. inhibens strain $\mathrm{K}^{\top}$ genome sequencing project details

\begin{tabular}{lll}
\hline MIGS ID & Property & Term \\
\hline MIGS-31 & Finishing quality & Improved High-Quality Draft \\
MIGS-28 & Libraries used & PacBio \\
MIGS-29 & Sequencing platforms & PacBio \\
MIGS-31.2 & Fold coverage & 273.1× \\
MIGS-30 & Assemblers & HGAP v.2.1.1 \\
MIGS-32 & Gene calling method & Prodigal 2.5 \\
& Locus Tag & BR65 \\
& Genbank ID & JQIV01000006.1 \\
& Genbank Date of Release & 16 August 2015 \\
& GOLD ID & Gp0042580 \\
& BIOPROJECT & PRJNA234895 \\
& Source material identifier & DSM 13024 \\
MIGS-13 & Project relevance & Environmental \\
& &
\end{tabular}




\section{Growth conditions and genomic DNA preparation}

Strain $\mathrm{K}^{\mathrm{T}}$ was grown to stationary phase by incubation for $36 \mathrm{~h}$ at $20{ }^{\circ} \mathrm{C}$ in TSY medium without shaking [8]. DNA was isolated from $100 \mathrm{~mL}$ of culture using a CTAB bacterial genomic DNA isolation method following the protocol recommended by JGI [21]. DNA fragment size and quality was confirmed by agarose gel electrophoresis and DNA was quantified by fluorometry (Qubit fluorometer, Invitrogen).

\section{Genome sequencing and assembly}

The draft genome of Carnobacterium inhibens K1 was generated at the DOE Joint genome Institute using the
Pacific Biosciences sequencing technology [19]. A PacBio SMRTbell $^{\text {TM }}$ library was constructed and sequenced on the PacBio RS platform, which generated 252,358 filtered sub-reads totaling $752.5 \mathrm{Mbp}$. All general aspects of library construction and sequencing performed at the JGI can be found at (http://www.jgi.doe.gov). The raw reads were assembled using HGAP (version: 2.1.1) [22]. The final draft assembly contained six contigs in six scaffolds, totaling 2.7 Mbp in size. The input read coverage was $273.1 \times$.

\section{Genome annotation}

The assembled sequence was annotated using the JGI prokaryotic annotation pipeline [23] and was further
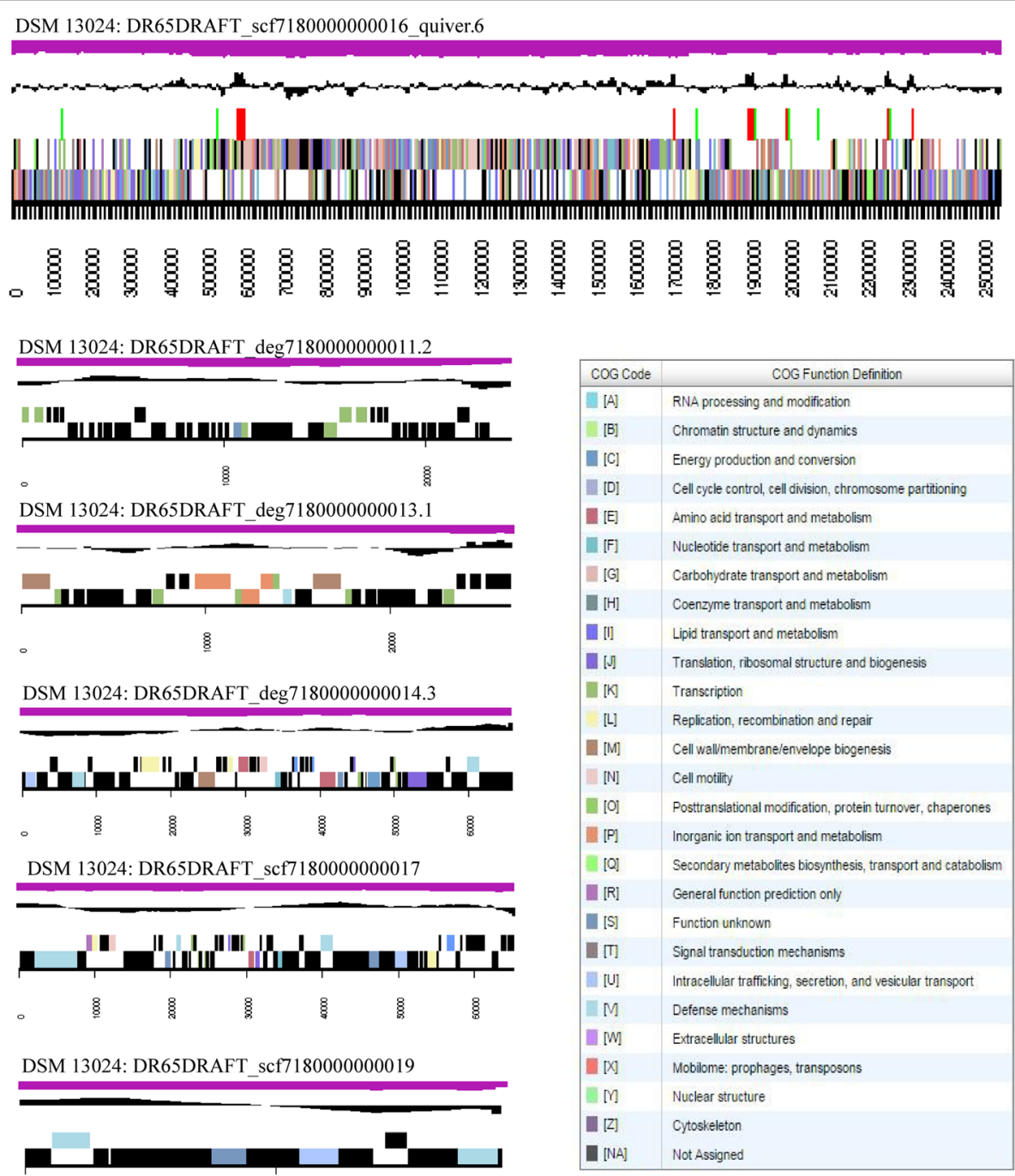

Fig. 3 Graphical map of the six scaffolds assembled for the genome of Carnobacterium inhibens K1T, DSM 13024. From top to bottom, the scaffolds are: DSM 13024: DR65DRAFT_scf7180000000016_quiver.6, DSM 13024: DR65DRAFT_deg7180000000011.2, DSM 13024: DR65DRAFT_deg7180000000013.1, DSM 13024: DR65DRAFT_deg7180000000014.3, DSM 13024: DR65DRAFT_scf71800000000017, and DSM 13024: DR65DRAFT_scf7180000000019. From bottom to the top of each scaffold: Genes on forward strand (color by COG categories), Genes on reverse strand (color by COG categories), RNA genes (tRNAs green, rRNAs red, other RNAs black), GC content, GC skew 
reviewed using the Integrated Microbial Genomes - Expert Review platform [24]. Genes were identified using Prodigal [25], followed by a round of manual curation using GenePRIMP [26] for finished genomes and Draft genomes in fewer than 10 scaffolds. The predicted CDSs were translated and used to search the National Center for Biotechnology Information nonredundant database, UniProt, TIGRFam, Pfam, KEGG, COG, and InterPro databases. The tRNAScanSE tool [27] was used to find tRNA genes, whereas ribosomal RNA genes were found by searches against models of the ribosomal RNA genes built from SILVA [28]. Other non-coding RNAs such as the RNA components of the protein secretion complex and the RNase $\mathrm{P}$ were identified by searching the genome for the corresponding Rfam profiles using INFERNAL [29]. Additional gene prediction analysis and manual functional annotation was performed within the Integrated Microbial Genomes platform [23] developed by the Joint Genome Institute, Walnut Creek, CA, USA.

\section{Genome properties}

The genome includes five smaller contigs, for a total size of 201,043 bp, and one large contig of 2,547,565 bp (34.85\% GC content) (Fig. 3). For the genome, 2737 genes were predicted, 2621 of which are protein-coding genes. Of these, 2151 were assigned to a putative function with the remaining 470 genes annotated as hypothetical proteins. 1838 protein coding genes belong to paralogous families in this genome, corresponding to a gene content redundancy of $67.15 \%$. The statistics of the genome are summarized in Tables 3 and 4. Examination of the sequence data for the five small contigs revealed a variety of putative genes encoding plasmid

Table 3 Genome statistics

\begin{tabular}{lll}
\hline Attribute & Value & \% of Total \\
\hline Genome size (bp) & $2,748,608$ & 100.00 \\
DNA coding (bp) & $2,356,497$ & 85.73 \\
DNA G + C (bp) & 957,950 & 34.85 \\
DNA scaffolds & 6 & 100.00 \\
Total genes & 2737 & 100.00 \\
Protein coding genes & 2621 & 95.76 \\
RNA genes & 116 & 4.24 \\
Pseudo genes & 66 & 2.41 \\
Genes in internal clusters & 515 & 18.82 \\
Genes with function prediction & 2151 & 78.59 \\
Genes assigned to COGs & 1900 & 69.42 \\
Genes with Pfam domains & 2196 & 80.23 \\
Genes with signal peptides & 113 & 4.13 \\
Genes with transmembrane helices & 691 & 25.25 \\
CRISPR repeats & 0 & 0 \\
\hline
\end{tabular}

Table 4 Number of genes associated with general COG functional categories

\begin{tabular}{|c|c|c|c|}
\hline Code & Value & $\%$ age & Description \\
\hline J & 196 & 9.36 & Translation, ribosomal structure and biogenesis \\
\hline A & 25 & 1.20 & RNA processing and modification \\
\hline K & 186 & 8.89 & Transcription \\
\hline L & 101 & 4.83 & Replication, recombination and repair \\
\hline B & 19 & 0.91 & Chromatin structure and dynamics \\
\hline D & 32 & 1.53 & $\begin{array}{l}\text { Cell cycle control, Cell division, chromosome } \\
\text { partitioning }\end{array}$ \\
\hline V & 71 & 3.39 & Defense mechanisms \\
\hline T & 78 & 3.73 & Signal transduction mechanisms \\
\hline M & 113 & 5.40 & Cell wall/membrane biogenesis \\
\hline N & 51 & 2.44 & Cell motility \\
\hline$U$ & 22 & 1.05 & Intracellular trafficking and secretion \\
\hline O & 61 & 2.91 & $\begin{array}{l}\text { Posttranslational modification, protein turnover, } \\
\text { chaperones }\end{array}$ \\
\hline C & 71 & 3.39 & Energy production and conversion \\
\hline G & 186 & 8.89 & Carbohydrate transport and metabolism \\
\hline E & 163 & 7.79 & Amino acid transport and metabolism \\
\hline $\mathrm{F}$ & 96 & 4.59 & Nucleotide transport and metabolism \\
\hline $\mathrm{H}$ & 76 & 3.63 & Coenzyme transport and metabolism \\
\hline I & 80 & 3.82 & Lipid transport and metabolism \\
\hline$P$ & 102 & 4.87 & Inorganic ion transport and metabolism \\
\hline Q & 34 & 1.62 & $\begin{array}{l}\text { Secondary metabolites biosynthesis, transport } \\
\text { and catabolism }\end{array}$ \\
\hline $\mathrm{R}$ & 199 & 9.51 & General function prediction only \\
\hline S & 156 & 7.45 & Function unknown \\
\hline- & 837 & 30.58 & Not in COGs \\
\hline
\end{tabular}

functions such as: autonomous replication, mobilization, bacteriocin production and immunity, toxin-antitoxin systems, and $\mathrm{Hg}$ or $\mathrm{Cd} / \mathrm{Co}$ resistance cassettes; therefore it is reasonable to assume that these five small contigs represent plasmids.

\section{Conclusion}

Carnobacterium inhibens is widely distributed in the environment, having been isolated from Atlantic salmon [14, 30], biogas slurry [31], a medicinal plant [32], and Siberian permafrost $[8,15]$. In this communication we report an improved high-quality draft genome sequence of Carnobacterium inhibens subsp. inhibens strain $\mathrm{K}^{\mathrm{T}}\left(=\mathrm{DSM} 13024^{\mathrm{T}}=\mathrm{JCM} 16168^{\mathrm{T}}\right)$. Genome analysis of this strain demonstrated a single presumed chromosome and at least five putative extrachromosomal elements.

\section{Acknowledgments}

This work was conducted as part of the Community Sequencing Program (CSP-1165) under the auspices of the US Department of Energy Joint Genome Institute, a DOE Office of Science User Facility supported by the 
Office of Science of the U.S. Department of Energy under Contract No. DEACO2-05CH11231.

\section{Authors' contributions}

WN supplied DNA and background information for this project and contributed to the assembly of the manuscript with CLD, AC, and NK NS coordinated the project and all other authors were involved in either sequencing the genome and/or editing the paper. All authors read and approved the final manuscript.

\section{Competing interests}

The authors declare that they have no competing interests.

\section{Author details}

${ }^{1}$ Department of Microbiology and Cell Science, Institute of Food and Agricultural Sciences, University of Florida, Merritt Island, FL 32953, USA. ${ }^{2}$ DOE Joint Genome Institute, Walnut Creek, CA, USA. ${ }^{3}$ Biological Data Management and Technology Center, Lawrence Berkeley National Laboratory, Berkeley, CA, USA. ${ }^{4}$ Department of Biological Sciences, Faculty of Science, King Abdulaziz University, Jeddah, Saudi Arabia.

\section{Received: 7 October 2015 Accepted: 31 August 2016}

\section{Published online: 08 September 2016}

\section{References}

1. Collins MD, Farrow JAE, Phillips BA, Ferusu S, Jones D. Classification of Lactobacillus divergens, Lactobacillus piscicola, and some catalase-negative, asporogenous, rod-shaped bacteria from poultry in a new genus, Carnobacterium. Int J Syst Bacteriol. 1987;37:310-6.

2. Schillinger U, Holzapfel WH. The genus Carnobacteriumm. In: Wood BJB, Holzapfel WH, editors. The Genera of Lactic Acid Bacteria. Volume 2 Springer Science+Business Dordrecht; 1995. p. 307-26.

3. Hammes WP, Hertel C. The genera Lactobacillus and Carnobacterium. In: Dworkin M, Falkow S, Rosenberg E, Schliefer K-H, Staeckebrandt E, editors. The Prokaryotes. Volume 4. 3rd ed. Singapore: Springer; 2006. p. 320-403.

4. Leisner JJ, Laursen BG, Prevost H, Drider D, Dalgaard P. Carnobacterium: positive and negative effects in the environment and in foods. FEMS Microbiol Rev. 2007;31:592-613.

5. Franzmann PD, Höpfel P, Weiss N, Tindall BJ. Psychrotrophic, lactic acidproducing bacteria from anoxic waters in Ace Lake, Antarctica: Carnobacterium funditum sp. nov. and Carnobacterium alterfunditum sp. nov. Arch Microbiol. 1991;156:255-62.

6. Snauwaert I, Hoste B, De Bruyne K, Peeters K, De Vuyst L, Willems A, Vandamme P. Carnobacterium iners sp. nov., a psychrophilic, lactic acidproducing bacterium from the littoral zone of an Antarctic pond. Int J Syst Evol Microbiol. 2013;63:1370-5.

7. Pikuta EV, Marsic D, Bej A, Tang J, Krader P, Hoover RB. Carnobacterium pleistocenium sp. nov., a novel psychrotolerant, facultative anaerobe isolated from permafrost of the Fox Tunnel in Alaska. Int J Syst Evol Microbiol. 2005; 55:473-8.

8. Nicholson WL, Zhalnina K, Oliveira RR, Triplett EW. Proposal to rename Carnobacterium inhibens to Carnobacterium inhibens subsp. inhibens subsp. nov., and description of Carnobacterium inhibens subsp. gilichinskyi subsp. nov., a novel psychrotolerant bacterium isolated from Siberian permafrost. Int J Syst Evol Microbiol. 2015;65:556-61.

9. Voget S, Klippel B, Daniel R, Antranikian G. Complete genome sequence of Carnobacterium sp. 17-4. J Bacteriol. 2011;193:3403-4.

10. Leisner JJ, Hansen MA, Larsen MH, Hansen L, Ingmer H, Sorensen SJ. The genome sequence of the lactic acid bacterium, Carnobacterium maltaromaticum ATCC 35586 encodes potential virulence factors. Int J Food Microbiol. 2012;152:107-15.

11. Cailliez-Grimal C, Chaillou S, Anba-Mondoloni J, Loux V, Afzal MI, Rahman A, Kergourlya G, Champomier-Vergès MC, Zagorec M, Dalgaard $P$, et al. Complete chromosome sequence of Carnobacterium maltaromaticum LMA 28. Genome Announc. 2013;1. doi: 10.1128/genomeA.00115-12.

12. Leonard MT, Panayotova N, Farmerie WG, Triplett EW, Nicholson WL. Complete genome sequence of Carnobacterium gilichinskyi strain WN1359 (DSM 27470). Genome Announc. 2013;1. doi: 10.1128/genomeA.00985-13.

13. Whon TW, Hyun D-W, Nam Y-D, Kim MS, Song E-J, Jang YK, Jung ES, Shin N-R, Oh JS, Kim PS, et al. Genomic and phenotypic analyses of Carnobacterium jeotgali strain $\mathrm{MS3}^{\top}$, a lactate producing candidate biopreservative bacterium isolated from salt-fermented shrimp. FEMS Microbiol Lett. 2015;362(10). doi:10. 1093/femsle/fnv058.

14. Jöborn A, Dorsch M, Olsson JC, Westerdahl A, Kjelleberg S. Carnobacterium inhibens sp. nov., isolated from the intestine of Atlantic salmon (Salmo salar). Int J Syst Bacteriol. 1999;49:1891-8.

15. Nicholson WL, Krivushin K, Gilichinsky D, Schuerger AC. Growth of Carnobacterium spp. from permafrost under low pressure, temperature, and anoxic atmosphere has implications for Earth microbes on Mars. Proc Natl Acad Sci U S A. 2013;110:666-71.

16. Benardini JN, Sawyer J, Venkateswaran K, Nicholson WL. Spore UV and acceleration resistance of endolithic Bacillus pumilus and Bacillus subtilis isolates obtained from Sonoran desert basalt: implications for lithopanspermia. Astrobiology. 2003;3:709-17.

17. Altschul S, Madden T, Schaffer A, Zhang J, Zhang Z, Miller W, Lipman D. Gapped BLAST and PSI-BLAST: a new generation of protein database search programs. Nucleic Acids Res. 1997;25:3389-402.

18. Reddy TB, Thomas AD, Stamatis D, Bertsch J, Isbandi M, Jansson J, Mallajosyula J, Pagani I, Lobos EA, Kyrpides NC. The Genomes OnLine Database (GOLD) v.5: a metadata management system based on a four level (meta) genome project classification. Nucleic Acids Res. 2015:43:D1099-106.

19. Eid J, Fehr A, Gray J, Luong K, Lyle J, Otto G, Peluso P, Rank D, Baybayan P, Bettman $B$, et al. Real-time DNA sequencing from single polymerase molecules. Science. 2009;323:133-8.

20. Field D, Garrity G, Gray T, Morrison N, Selengut J, Sterk P, Tatusova T, Thomson N, Allen MJ, Angiuoli SV, et al. The minimum information about a genome sequence (MIGS) specification. Nat Biotechnol. 2008;26:541-7.

21. DOE Joint Genome Institute user home. http://www.jgi.doe.gov.

22. Chin CS, Alexander DH, Marks P, Klammer AA, Drake J, Heiner C, Clum A, Copeland A, Huddleston J, Eichler EE, et al. Nonhybrid, finished microbial genome assemblies from long-read SMRT sequencing data. Nat Methods. 2013;10:563-9.

23. The Integrated Microbial Genomes (IMG) platform. http://img.jgi.doe.gov.

24. Markowitz VM, Mavromatis K, Ivanova NN, Chen IM, Chu K, Kyrpides NC. IMG ER: a system for microbial genome annotation expert review and curation. Bioinformatics. 2009;25:2271-8.

25. Hyatt $D$, Chen GL, Locascio PF, Land ML, Larimer FW, Hauser LJ. Prodigal: prokaryotic gene recognition and translation initiation site identification. BMC Bioinformatics. 2010;11:119.

26. Pati A, Ivanova NN, Mikhailova N, Ovchinnikova G, Hooper SD, Lykidis A, Kyrpides NC. GenePRIMP: a gene prediction improvement pipeline for prokaryotic genomes. Nat Methods. 2010;7:455-7.

27. Lowe TM, Eddy SR. tRNAscan-SE: a program for improved detection of transfer RNA genes in genomic sequence. Nucleic Acids Res. 1997;25:955-64.

28. Pruesse E, Quast C, Knittel K, Fuchs BM, Ludwig W, Peplies J, Glöckner FO. SILVA: a comprehensive online resource for quality checked and aligned ribosomal RNA sequence data compatible with ARB. Nucleic Acids Res. 2007;35:7188-96.

29. INFERNAL: Inference of RNA alignments. http://eddylab.org/infernal/. Accessed 6 Sept 2016.

30. Ringo E, Sperstad S, Kraugerud OF, Krogdahl A. Use of 16S rRNA gene sequencing analysis to characterize culturable intestinal bacteria in Atlantic salmon (Salmo salar) fed diets with cellulose or non-starch polysaccharides from soy. Aquac Res. 2008;39:1087-100.

31. Feng $N$, Hao WH, Lei HX, Wei XH. Carnobacterium inhibens isolated from biogas slurry of Tianzhu county of Gansu province. In: National Center for Biotechnology Information (NCBI), August 10, 2013 edition. 2013.

32. Bibi F. Isolation of antagonistic bacteria from medicinal plant. In: June 28 , 2015 edition. National Center for Biotechnology Information (NCBI). 2015.

33. Coordinators NR. Database resources of the National Center for Biotechnology Information. Nucleic Acids Res. 2014;42:D7-D17.

34. Gibbons NE, Murray RGE. Proposals concerning the higher taxa of bacteria. Int J Syst Bacteriol. 1978;28:1.

35. Editor L. List of new names and new combinations previously effectively, but not validly, published. List no. 132. Int J Syst Evol Microbiol. 2010;60:469-72.

36. Ludwig W, Schleifer K-H, Whitman WB. Class I. Bacilli class nov. Bergey's Manual Syst Bacteriol. 2009;3:19-20.

37. Ludwig W, Schleifer K-H, Whitman WB. Order II. Lactobacillales ord. nov. Bergey's Manual Syst Bacteriol. 2009;3:464.

38. Ludwig W, Schleifer K-H, Whitman WB. Family III. Carnobacteriaceae fam. nov. Bergey's Manual of Syst Bacteriol. 2009;3:549.

39. Ashburner M, Ball CA, Blake JA, Botstein D, Butler H, Cherry JM, Davis AP, Dolinski K, Dwight SS, Eppig JT, et al. Gene ontology: tool for the unification of biology. The Gene Ontology Consortium. Nat Genet. 2000;25:25-9. 